\title{
Adsorption kinetic studies for removal of methylene blue using activated carbon prepared from sugar beet pulp
}

\author{
D. $\mathrm{Li}^{1} \cdot$ J. $\operatorname{Yan}^{1} \cdot$ Z. $\mathrm{Liu}^{1} \cdot$ Z. $\mathrm{Liu}^{2,3}$
}

Received: 8 February 2016/Revised: 13 April 2016/Accepted: 3 May 2016/Published online: 17 May 2016

(C) Islamic Azad University (IAU) 2016

\begin{abstract}
Sugar beet pulp is an abundant, renewable and low-cost precursor for production of activated carbon. In the present study, sugar beet pulp based activated carbon was prepared by using phosphoric acid as activating agent for adsorption of methylene blue. The conditions of preparation process had a significant influence on the adsorption of methylene blue, and the optimal preparation conditions were obtained as follows: liquid-to-solid ratio of 5 , temperature of $450{ }^{\circ} \mathrm{C}$ and phosphoric acid concentration of $3 \mathrm{~mol} / \mathrm{L}$. The properties of sugar beet pulp based activated carbon were characterized by nitrogen adsorption isotherm. The adsorption increases as the increase of contact time, adsorption temperature and $\mathrm{pH}$, and initial concentration of methylene blue. Batch kinetic studies showed that an equilibrium time of $100 \mathrm{~min}$ was needed for the adsorption, and the adsorbance of methylene blue is $244.76 \mathrm{mg} / \mathrm{g}$ at equilibration. Kinetic models, Weber's pore diffusion model and Boyd's equation were applied to the experimental data to study the mechanism of adsorption and the controlled step. The results showed that the adsorption kinetics followed the pseudosecond-order type kinetic model, intraparticle diffusion was not the rate-limiting mechanism and adsorption process was controlled by film diffusion.
\end{abstract}

D. $\mathrm{Li}$

1sx20131120a@163.com

1 College of Chemical Engineering, Xinjiang Agricultural University, Urumchi 830052, Xinjiang, People's Republic of China

2 School of Chemistry and Chemical Engineering, Shihezi University, Shihezi 832003, Xinjiang, People's Republic of China

3 Key Laboratory for Green Processing of Chemical Engineering of Xinjiang Bintuan, Shihezi 832003, Xinjiang, People's Republic of China
Keywords Sugar beet pulp - Activated carbon - Methylene blue $\cdot$ Adsorption kinetic $\cdot$ Intraparticle diffusion

\section{Introduction}

Dyes are widely used in the industries of dyestuffs, paper, plastics, textile, leather, cosmetics and food, which generate appreciable amount of wastewater. However, dyes have been considered harmful organic compounds for environment, and most of the residual dyes are resistant to biodegradation processes and toxic, which caused water unfit (Kaur et al. 2015). Several methods involved biological, physical, chemical and associated technologies have been reported for dyes removal. Among the numerous techniques, adsorption is the procedure of choice and gives the best results as it can be used to remove different types of dyes, simultaneously. Currently, adsorption by activated carbon (AC) has been considered to be the most widely used and effective physical method (Alkhatib et al. 2015; Kaur et al. 2015; Thitame and Shukla 2016).

Commercial AC usually generated from non-renewable materials, which destroy environment and increase the running costs (Arulkumar et al. 2011). Therefore, various abundance, renewability, cost-effectiveness and ecofriendly materials have been attracting interests of researchers. In recent years, agricultural wastes have been employed to prepare AC, such as the sugar beet pulp (Dursun et al. 2013; Ma et al. 2014) and corn wastes (Abdel-Ghani et al. 2015). From the literature, it is clear that the starting material significantly influences physical and chemical properties of $\mathrm{AC}$ and adsorption property as a result.

Sugar beet, which is the by-product of sucrose production, was low commercial value but only for animal feed ( $\mathrm{Li}$ et al. 2013). Sugar beet pulp has a respectable content of 
cellulose, hemicellulose and lignin, which was suitable for preparation of AC. To our knowledge, some researchers have used sugar beet pulp as starting material to prepare AC and investigated their adsorption properties (Ozer and Tumen 2003; Samadi et al. 2009; Demiral and Gündüzoğlu 2010; Dursun et al. 2013), and few literatures focused on the separation of dyes, but only for heavy metal removal.

The objective of the present study is to prepare sugar beet pulp based activated carbon (SBPAC) and employ the resulted $\mathrm{AC}$ for removal of methylene blue (MB) from aqueous solutions. In order to obtain the optimal preparation conditions, effects of independent variables on the MB adsorption were studied. Batch adsorption experiments were carried out to evaluate the adsorption processes in a wide range of operating conditions. In addition, the adsorption kinetics and adsorption mechanism were made deep analysis.

\section{Materials and methods}

\section{Materials}

Sugar beet pulp was obtained from LüYuan Sugar Industry Co., Ltd. (Hejing, Xinjiang Uygur Autonomous Region, China). The pulp was crushed and separated by $40-$ mesh screen. The $\mathrm{H}_{3} \mathrm{PO}_{4}$ and other reagents were of analytical grade without further treatment.

\section{AC preparation}

The powder of sugar beet pulp was infused by $\mathrm{H}_{3} \mathrm{PO}_{4}$ of different concentrations (1, 2, 3, 4 and $5 \mathrm{~mol} / \mathrm{L})$ with different liquid-to-solid ratios (LSR, 2, 3.5, 5, 6.5 and 8) for $5 \mathrm{~h}$ at room temperature. The carbonization impregnation step was carried out at temperature of $110{ }^{\circ} \mathrm{C}$ for $12 \mathrm{~h}$. The obtained products were activated under the same condition as carbonization but at different temperatures (350, 400, 450,500 and $500{ }^{\circ} \mathrm{C}$ ), after the corresponding temperature reached, the activation held for time of $0.5,1,1.5,2$ and $2.5 \mathrm{~h}$. Then, the final product was cooled to room temperature and washed with hot deionized water until the $\mathrm{pH}$ of the washing solution reached 7. The pore structure of SBPAC was determined by nitrogen adsorption isotherm at $77 \mathrm{~K}$ using BET equation. The surface functional groups were detected on an AVATAR 360 Fourier transform spectrometer with a scanning range of $4000-500 \mathrm{~cm}^{-1}$.

\section{Effect of independent variables on the adsorbance and yield of SBPAC}

After the treatment by hot deionized water, the samples were heated to a constant weight, and the yield was calculated.
In order to study the effects of factors on the adsorption of $\mathrm{MB}, 0.2 \mathrm{~g}$ samples were added into each flask, which contained $150 \mathrm{~mL} \mathrm{MB}$ solution with concentration of $400 \mathrm{mg} / \mathrm{L}$, and then, the flasks were placed in a water bath shaker with a constant speed of $200 \mathrm{rpm}$, until adsorption equilibrium was obtained.

\section{Equilibrium studies}

Equilibrium studies were carried out at temperature of $20{ }^{\circ} \mathrm{C}$ in a set of conical beaker $(250 \mathrm{~mL})$ with different initial $\mathrm{MB}$ concentrations. $0.2 \mathrm{~g}$ of SBPAC was added into each flask, which contained MB solution with the initial $\mathrm{pH}$ value of 8 . Then, the flasks were placed in a water bath shaker with a constant speed of $200 \mathrm{rpm}$. The processes were over after $3 \mathrm{~h}$ of adsorption, the obtained solutions were centrifugalized to gain the final MB solution and the final concentration of $\mathrm{MB}$ was measured by a UV-Vis spectrophotometer. The amount of MB adsorbed at equilibrium, $q_{e}(\mathrm{mg} / \mathrm{g})$ was obtained as follows:

$q_{e}=\frac{\left(C_{0}-C_{e}\right) V}{W}$

where $C_{0}$ and $C_{e}$ are the initial and final concentration of MB solution, respectively; $V$ is the volume of solution; and the $W$ is the weight of SBPAC added into the flasks.

In order to study the effect of initial $\mathrm{pH}$ on the adsorption of $\mathrm{MB}$, the studies were carried out at temperature of $20{ }^{\circ} \mathrm{C}$ for $4 \mathrm{~h}$, and the initial $\mathrm{pH}$ on the adsorption of $\mathrm{MB}$ was taken by adjusting $\mathrm{pH}$ value of solution with $0.1 \mathrm{M}$ $\mathrm{NaOH}$ and $\mathrm{HCl}$ solution.

The effect of contact time and initial concentration on the adsorption of $\mathrm{MB}$ was also studied as the significance influence of $\mathrm{MB}$ adsorption. In total, $150 \mathrm{~mL}$ of $\mathrm{MB}$ solution with initial concentration of 300, 400, 500 and $600 \mathrm{mg} / \mathrm{L}$ was prepared, and $0.2 \mathrm{~g}$ of SBPAC was added into each flask, which then placed in a water bath shaker with a constant speed of $200 \mathrm{rpm}$ at temperature of $20{ }^{\circ} \mathrm{C}$, until equilibrium point was reached. All the initial $\mathrm{pH}$ value of solution was 8 adjusted by $0.1 \mathrm{M} \mathrm{NaOH}$ and $\mathrm{HCl}$ solution and without any adjustment in adsorption process.

In order to obtain the effect of temperature on adsorption of $\mathrm{MB}$, experiments were carried out at temperature of $10,20,30,40$ and $50{ }^{\circ} \mathrm{C}$, and other operating parameters were kept constant.

\section{Kinetic studies}

For the studies of kinetics, same processes were developed, but the samples were taken at preset time interval. The amount of MB adsorbed at different time, $q_{t}(\mathrm{mg} / \mathrm{g})$, was obtained as follows: 
$q_{t}=\frac{\left(C_{0}-C_{t}\right) V}{W}$

where $C_{t}$ is the concentration of $\mathrm{MB}$ at corresponding time, $t$ (min).

The pseudo-first-order (Langergren and Svenska 1898) and pseudo-second-order equations (Ho and McKay 1998) were considered for adsorption kinetics in present study. The kinetics equation was defined as:

$\frac{\mathrm{d} q}{\mathrm{~d} t}=k_{1}\left(q_{e}-q_{t}\right)$

$\frac{\mathrm{d} q}{\mathrm{~d} t}=k_{2}\left(q_{e}-q_{t}\right)^{2}$

where $q_{e}(\mathrm{mg} / \mathrm{g})$ and $q_{t}(\mathrm{mg} / \mathrm{g})$ stand for the amounts of adsorbate adsorbed at equilibrium and at $t$ time, respectively; $k_{1}(\mathrm{mg} / \mathrm{g} \mathrm{h})$ and $k_{2}(\mathrm{mg} / \mathrm{g} \mathrm{h})$ represent the adsorption rate constant of pseudo-first-order and pseudo-secondorder equation, respectively.

The kinetic results were further analyzed by using the intraparticle diffusion model (Eq. 5):

$q_{t}=k t^{1 / 2}+C_{i}$

where $k$, the rate parameter of different stages, is obtained from the slope of the straight line of $q_{t}$ versus $t^{1 / 2} \cdot C_{i}$ represents the boundary-layer effect.

In general, the adsorption mechanism of adsorption of the adsorbate molecules on the interior of the porous adsorbent is assumed to be very fast and can be considered negligible. In order to distinguish the mechanism of film and particle diffusion, Boyd's model (Eq. 6) was employed to analyze the kinetic results.

$B_{t}=-0.4977-\ln \left(1-\frac{q_{t}}{q_{e}}\right)$

\section{Results and discussion}

\section{Effects of independent variables on yield and adsorption of $\mathrm{MB}$}

In order to find the best preparation condition for $\mathrm{MB}$ adsorption, four independent variables, including LSR, temperature and time of activation and concentration of $\mathrm{H}_{3} \mathrm{PO}_{4}$, were chosen from published data (Liu et al. 2010), and the results are listed in Fig. 1. From Fig. 1a and d, it is clear that the yield was slightly influenced by LSR and concentration of $\mathrm{H}_{3} \mathrm{PO}_{4}$, and all the value of yield ranges from $33.27 \%$ to $41.86 \%$. A significant decreasing trend of yield is shown in Fig. $1 \mathrm{~b}$ and $\mathrm{c}$, and the range was between $10.41 \%$ and $47.83 \%$, because the fierce reaction at hightemperature level resulted in a greater weight loss of the carbon precursor. The variation range of results was larger than results published by Ma et al. (2014) who prepared SBPAC via microwave-induced $\mathrm{KOH}$ activation, and the main reasons for this complexion are the operation of vacuumizing and the choice of activation condition in the process. Similar results were obtained by K1liç et al. (2012) who prepared $\mathrm{AC}$ from Euphorbia rigida by chemical activation with $\mathrm{ZnCl}_{2}, \mathrm{~K}_{2} \mathrm{CO}_{3}, \mathrm{NaOH}$ and $\mathrm{H}_{3} \mathrm{PO}_{4}$.

For screening out the relatively optimum condition of preparing SBPAC, adsorption properties of $\mathrm{MB}$ were studied. From Fig. 1, it is visible that the capacity of MB firstly increased and then decreased as the increasing in LSR, activation temperature and time and concentration of $\mathrm{H}_{3} \mathrm{PO}_{4}$. Similar trends were shown by Ma et al. (2014) and Xiao et al. (2012). But an ascendant trend and smooth trend were obtained by Tongpoothorn et al. (2011) and Wang et al. (2009), respectively. With the increase in variables, the reactions become more intensive, which contribute to the development of internal microporous cavities, resulting in increasing surface area. The adsorption property of MB on SBPAC is better than that operated by Cherifi et al. (2013).

Based on data of influences of four variables on the yield and adsorption property of $\mathrm{MB}$, the relatively optimum condition for preparing SBPAC was chosen as follows: LSR of 5 , activation temperature of $450{ }^{\circ} \mathrm{C}$, activation time of $60 \mathrm{~min}$ and the concentration of $\mathrm{H}_{3} \mathrm{PO}_{4}$ of $3 \mathrm{M}$. SBPAC was prepared under the above-mentioned conditions for the equilibrium and kinetics studies.

\section{Characterization}

The nitrogen adsorption-desorption curve is demonstrated in Fig. 2. As shown in Fig. 2, the adsorption isotherm curve was similar to a mixed type in the IUPAC classification, which was type I at low pressure and type IV at intermediate and high $P / P_{0}$. In the low-pressure stage, they are significant $\mathrm{N}_{2}$ uptake and characterize microporous materials. Then, an open keen presents, an inconspicuous plateau appears and a certain slope can be observed in the next part. The fact indicates that the microporosity translates to mesoporosity. Otherwise, a desorption hysteresis loop in the mesopores is presented due to adsorbate condensation. All the phenomena show a good agreement with the known data (Puziy et al. 2002; Kennedy et al. 2007; Tongpoothorn et al. 2011). Meanwhile, the porous structure parameters of the SBPAC are illustrated in Table 1. It can be observed that the BET surface area, micropore surface area, external surface area, Langmuir surface area, total pore volume, micropore volume and average pore size were $\quad 1029.31 \mathrm{~m}^{2} / \mathrm{g}, \quad 629.30 \mathrm{~m}^{2} / \mathrm{g}, \quad 290.03 \mathrm{~m}^{2} / \mathrm{g}$, $1391.46 \mathrm{~m}^{2} / \mathrm{g}, \quad 0.445 \mathrm{~cm}^{3} / \mathrm{g}, \quad 0.329 \mathrm{~cm}^{3} / \mathrm{g}$ and $23.93 \AA$, respectively. 

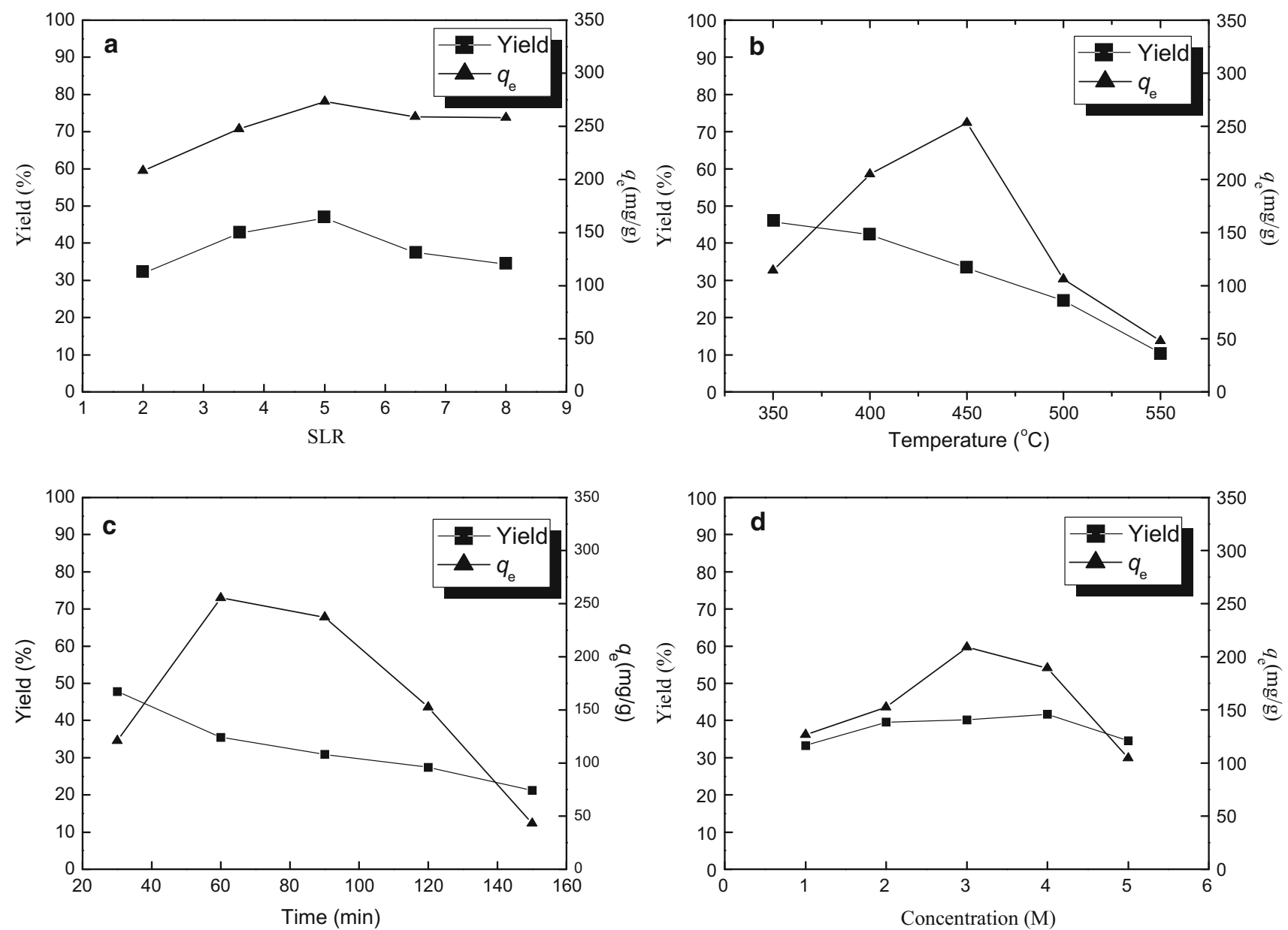

Fig. 1 Effects of independent variables on yield and adsorption of MB: a effect of LSR; $\mathbf{b}$ effect of temperature of activation; $\mathbf{c}$ effect of activation time; and $\mathbf{d}$ effect of concentration of $\mathrm{H}_{3} \mathrm{PO}_{4}$

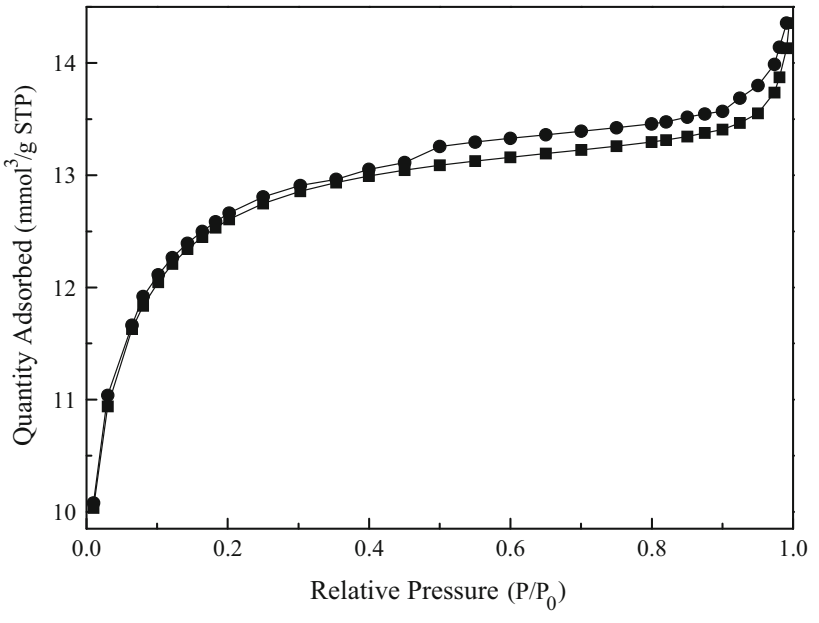

Fig. 2 Nitrogen adsorption-desorption isotherms of SBPAC

The FTIR spectra of SBPAC are shown in Fig. 3. The peak at $3447.47 \mathrm{~cm}^{-1}$ is characteristic of the stretching vibration of hydrogen bonded to the $-\mathrm{OH}$ groups (Yang
Table 1 Porous structure parameters of the SBPAC

\begin{tabular}{ll}
\hline Parameters & SBPAC \\
\hline BET surface area $\left(\mathrm{m}^{2} / \mathrm{g}\right)$ & 1029.31 \\
Micropore surface area $\left(\mathrm{m}^{2} / \mathrm{g}\right)$ & 629.30 \\
External surface area $\left(\mathrm{m}^{2} / \mathrm{g}\right)$ & 290.03 \\
Langmuir surface $a r e a\left(\mathrm{~m}^{2} / \mathrm{g}\right)$ & 1391.46 \\
Total pore volume $\left(\mathrm{cm}^{3} / \mathrm{g}\right)$ & 0.445 \\
Micropore volume $\left(\mathrm{cm}^{3} / \mathrm{g}\right)$ & 0.329 \\
Average pore size $(\AA)$ & 23.93 \\
\hline
\end{tabular}

et al. 2010). The signal at $2349.24 \mathrm{~cm}^{-1}$ was assigned to the $\mathrm{C} \equiv \mathrm{C}$ (alkynes) (Zhong et al. 2012). The bands between 1637.47 and $1408.86 \mathrm{~cm}^{-1}$ are assigned to the carbonyl group (Saka 2012). The band around $1044.88 \mathrm{~cm}^{-1}$ was assigned to $\mathrm{C}=\mathrm{O}$ functional groups of anhydrides (Zhong et al. 2012). The FTIR analysis revealed the presence of many surface functional groups such as hydroxyl groups and carbonyl group. 


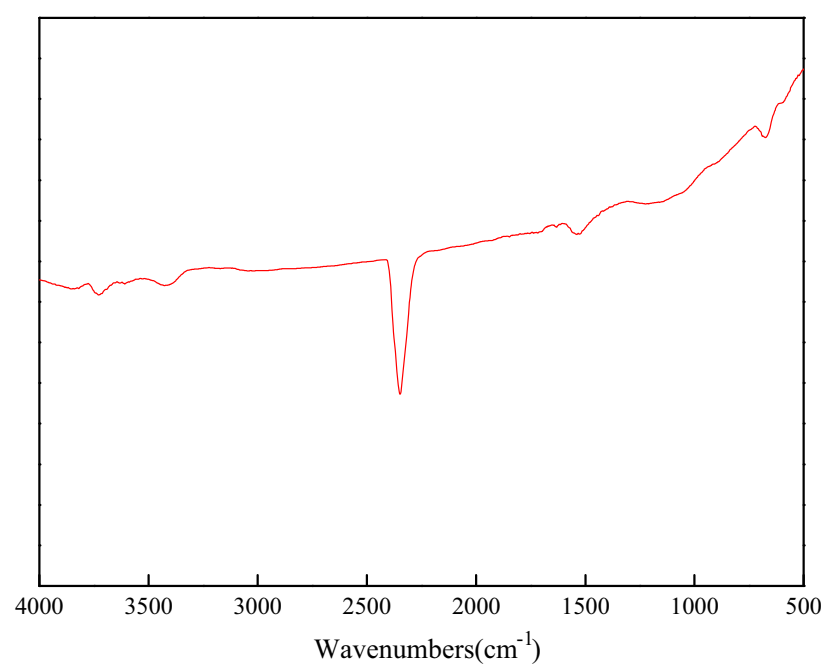

Fig. 3 FTIR spectra of SBPAC

\section{Equilibrium studies}

Figure 4 shows the equilibrium adsorption studies under different conditions. From Fig. $4 \mathrm{a}$, the effect of initial $\mathrm{pH}$ on the adsorption of $\mathrm{MB}$ was exhibited, and the increasing trend was obtained as the $\mathrm{pH}$ increases, the maximum adsorbance was obtained in $\mathrm{pH}$ of 8 , and then a flat appeared. It was caused by the positive charge in the surface of SBPAC, which prevents the adsorption of MB in acid medium, and the polarity of SBPAC changed by forming double layers when $\mathrm{pH}$ of the solution become neutral or alkalescence (Hameed and El-Khaiary 2008; Liao et al. 2011).

Figure $4 \mathrm{~b}$ shows the influence of temperature on $\mathrm{MB}$ adsorption uptake, and the adsorption uptake increased as the temperature increases from $10{ }^{\circ} \mathrm{C}$ to $50{ }^{\circ} \mathrm{C}$. This phenomenon may be caused by the fact that the adsorption reaction is an endothermic process, higher temperature promotes the MB to penetrate inside the sample pores, otherwise shrewd chemical interaction occurred between adsorbate and surface functional group of adsorbent (Hameed et al. 2009; Ahmad and Rahman 2011).

As shown in Fig. 4c, effect of contact time and initial concentration on the adsorption of MB was shown. It can be seen that the adsorption is rapid at the initial stage of adsorption, which was due to the fact that abundant surface sites exist for MB adsorption. With the passage of contact time, adsorption site sharply decreased which caused difficulty occurring in the adsorption process, and it must take a long time to reach equilibrium (Mohd Din et al. 2009). The adsorption uptakes at equilibrium increase from $190.22 \mathrm{mg} / \mathrm{g}$ to $250.01 \mathrm{mg} / \mathrm{g}$ as the initial concentration increases from $300 \mathrm{mg} / \mathrm{g}$ to $600 \mathrm{mg} / \mathrm{g}$. It is obvious that the initial
Fig. 4 Equilibrium studies: a effect of initial $\mathrm{pH}$ on the adsorption of MB; $\mathbf{b}$ effect of temperature on the adsorption of $\mathrm{MB}$; and $\mathbf{c}$ effect of contact time and initial concentration on the adsorption of MB
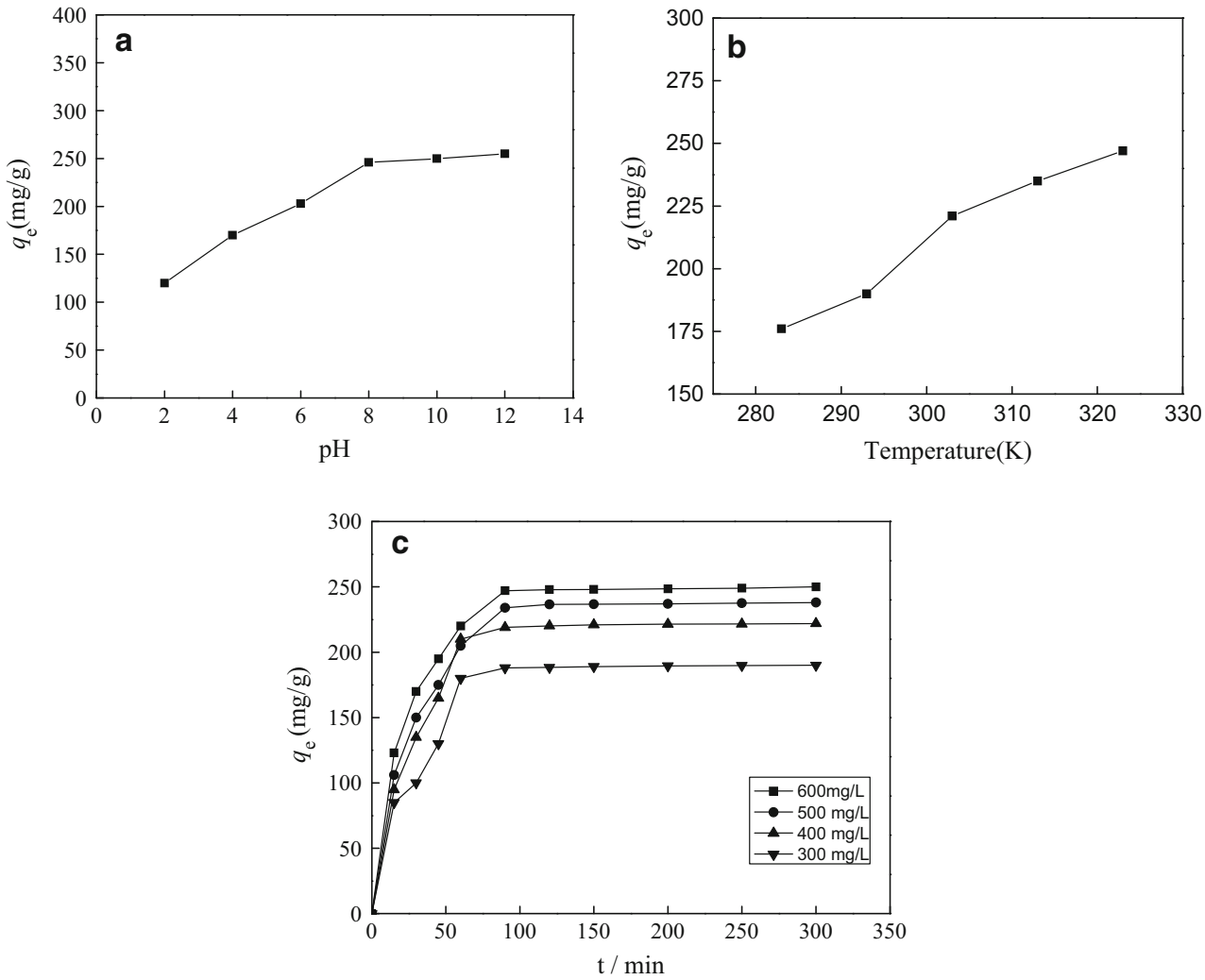
Table 2 Adsorption capacities of various agro-industrial waste materials and resulted AC

\begin{tabular}{lllll}
\hline Precursor & $\begin{array}{l}\text { Adsorption } \\
\text { capacities (mg/g) }\end{array}$ & References & $\begin{array}{l}\text { Adsorption capacities of } \\
\text { resulted AC (mg/g) }\end{array}$ & References \\
\hline Sugar beet pulp & 714.29 & $\begin{array}{l}\text { Vučurović et al. (2012) } \\
\text { Malekbala et al. (2012) }\end{array}$ & 250.01 & This work \\
Rice husk & 211 & McKay et al. (1999) & 40.5833 & Vadivelan and Kumar (2005) \\
Guava waster & 312.26 & Ponnusami et al. (2008) & 250 & Amri et al. (2012) \\
Cotton waster & 295.00 & McKay et al. (1999) & 193.50 & Deng et al. (2009) \\
Papaya seeds & 555.55 & Hameed (2009) & 97.09 & Collin and Lee (2009) \\
\hline
\end{tabular}
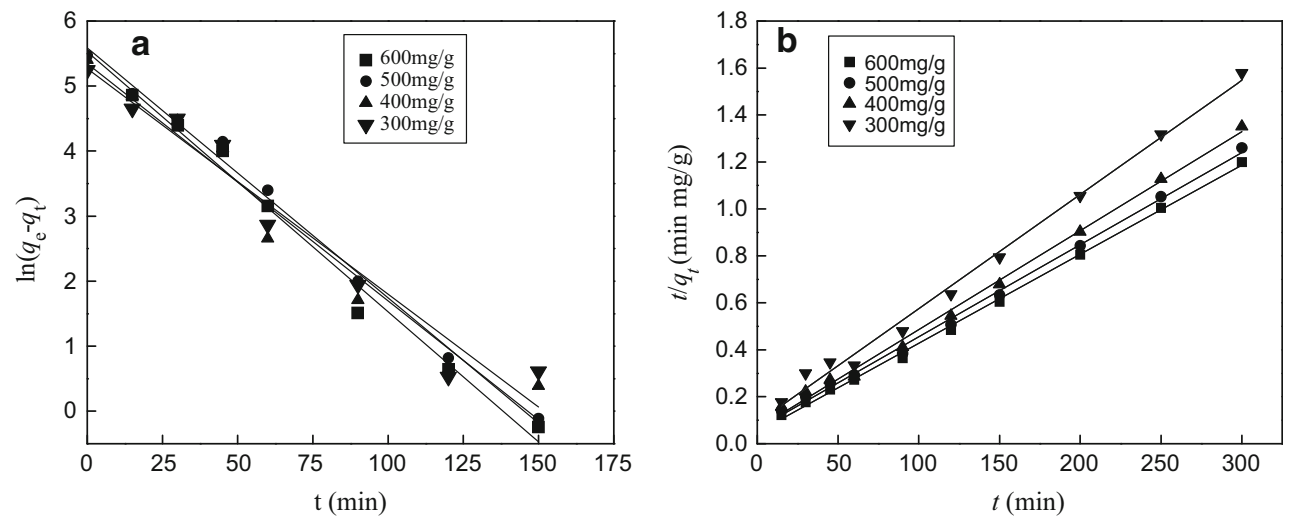

Fig. 5 Kinetic plot for the adsorption of MB on SBPAC: a pseudo-first-order kinetic model; b pseudo-second-order kinetic model

concentration can afford significant driving force to overcome the mass transfer resistance between the aqueous and solid phases (Hameed et al. 2009).

Compared with the work which used sugar beet pulp as sorbent (Vučurović et al. 2012), SBPAC showed a weaker adsorbance and this may be caused by the existing of functional group in precursor. Similar results were obtained from contrast of various agro-industrial waste materials and resulted AC (Table 2).

\section{Adsorption kinetics}

Pseudo-first-order and pseudo-second-order models have been proposed to predict the mechanism that MB may be adsorbed on SBPAC. The adsorption data were fitted using the plots of $\ln \left(q_{e}-q_{t}\right)$ against $t$ for pseudo-firstorder model and $t / q_{t}$ versus $t$ for pseudo-second-order model (Fig. 5; Table 3). From the fitting process, pseudosecond-order model shows a good agreement with experimental data and all the correlation coefficient are $>0.99$. Same result was obtained by Ahmad and Rahman (2011).

\section{Adsorption mechanism}

The kinetic results were further analyzed by using intraparticle diffusion model and Boyd's model. As shown in Fig. 6a, three adsorption stages of MB are observed. Due to the intense electrostatic attraction between $\mathrm{MB}$ and SBPAC, the first stage is an effectively adsorption. Then, a gradual adsorption is present in the second stage, which caused by intraparticle diffusion of MB molecules through the pores of SBPAC. The third stage was the final equilibrium stage as the intraparticle diffusion started to slow down, which is attributed to the high initial MB concentration (Wang et al. 2010). In addition, the plots were not linear during the time range, which indicated that intraparticle diffusion was not the only rate-limiting mechanism in the adsorption process.

Figure $6 \mathrm{~b}$ illustrates the Boyd's plots for adsorption of MB on SBPAC. All the lines for different initial concentrations did not pass through the origin, and the models do not show a good agreement with experimental data, which suggest that the adsorption process is controlled by film diffusion. 

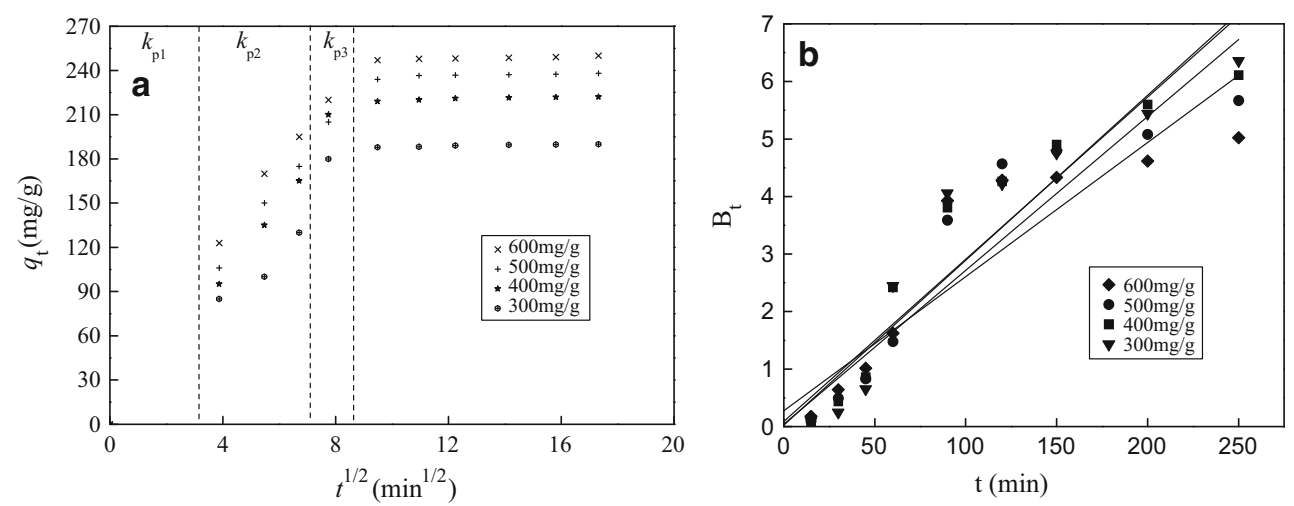

Fig. 6 Adsorption mechanism: a plot of intraparticle diffusion model for the adsorption of MB on SBPAC; b Boyd's plot for the adsorption of $\mathrm{MB}$ on SBPAC

Table 3 Pseudo-first-order and pseudo-second-order kinetic model parameters for the adsorption of MB on SBPAC

\begin{tabular}{llllll}
\hline$C_{0}(\mathrm{mg} / \mathrm{g})$ & \multicolumn{2}{l}{ Pseudo-first-order kinetic model } & & \multicolumn{2}{l}{ Pseudo-second-order kinetic model } \\
\cline { 2 - 3 } & $k_{1}(1 / \mathrm{min})$ & $R^{2}$ & & $k_{2}(\mathrm{~g} / \mathrm{mg} \mathrm{min})$ & $R^{2}$ \\
\hline 300 & 0.0345 & 0.953 & & 0.0027 & 0.992 \\
400 & 0.0365 & 0.964 & & 0.0027 & 0.999 \\
500 & 0.0384 & 0.976 & & 0.0029 & 0.997 \\
600 & 0.0399 & 0.973 & & 0.0030 & 0.998 \\
\hline
\end{tabular}

\section{Conclusion}

SBPAC was prepared from sugar beet pulp using phosphoric acid as an activating agent for adsorption of MB and was found to be suitable to remove MB. Preparation condition was found to significantly influence adsorption of $\mathrm{MB}$, and the adsorbance of MB was reached to maximum at the following independent conditions: LSR of 5, temperature of $450{ }^{\circ} \mathrm{C}$, time of $60 \mathrm{~min}$ and phosphoric acid concentration of $3 \mathrm{~mol} / \mathrm{L}$. The properties of SBPAC, including BET surface area, micropore surface area, external surface area, Langmuir surface area, total pore volume, micropore volume and average pore size, were characterized by nitrogen adsorption isotherm, and the values were $1029.31 \mathrm{~m}^{2} / \mathrm{g}, \quad 629.30 \mathrm{~m}^{2} / \mathrm{g}, 290.03 \mathrm{~m}^{2} / \mathrm{g}$, $1391.46 \mathrm{~m}^{2} / \mathrm{g}, \quad 0.445 \mathrm{~cm}^{3} / \mathrm{g}, 0.329 \mathrm{~cm}^{3} / \mathrm{g}$ and $23.93 \AA$, respectively. The adsorption of $\mathrm{MB}$ increases with the increase in contact time, adsorption temperature and $\mathrm{pH}$ and initial concentration of MB. The adsorption kinetics indicated that pseudo-second-order kinetic model fits well with the experimental data. From the future analysis of kinetic data by Boyd's model, adsorption of MB on SBPAC took place by film diffusion mechanism.

Acknowledgments The authors would like to gratefully acknowledge financial support from the prophase-sustentation fund of Xinjiang Agricultural University (No. XJAU201301) and National
Undergraduate Training Programs for Innovation and Entrepreneurship of China (No. 201410758033).

\section{References}

Abdel-Ghani N, El-Chaghaby G, Zahran E (2015) Pentachlorophenol (PCP) adsorption from aqueous solution by activated carbons prepared from corn wastes. Int $\mathrm{J}$ Environ Sci Technol 12(1):211-222

Ahmad MA, Rahman NK (2011) Equilibrium, kinetics and thermodynamic of Remazol Brilliant Orange 3R dye adsorption on coffee husk-based activated carbon. Chem Eng J 170(1):154-161

Alkhatib M, Mamun AA, Akbar I (2015) Application of response surface methodology (RSM) for optimization of color removal from POME by granular activated carbon. Int $\mathrm{J}$ Environ Sci Technol 12(4):1295-1302

Amri N, Alrozi R, Osman MS, Nasuha N, Aman NS (2012) Removal of methylene blue dye from aqueous solution using pink guava (Psidium guajava) waste-based activated carbon. In: IEEE Symposium on Humanities, Science and Engineering Research (SHUSER), pp 33-38

Arulkumar M, Sathishkumar P, Palvannan T (2011) Optimization of Orange $\mathrm{G}$ dye adsorption by activated carbon of Thespesia populnea pods using response surface methodology. J Hazard Mater 186(1):827-834

Cherifi H, Fatiha B, Salah H (2013) Kinetic studies on the adsorption of methylene blue onto vegetal fiber activated carbons. Appl Surf Sci 282:52-59

Collin JG, Lee MP (2009) Sorption kinetic studies of medical grade activated carbon prepared from papaya seeds. Mod Appl Sci 2(6): $115-123$ 
Demiral H, Gündüzoğlu G (2010) Removal of nitrate from aqueous solutions by activated carbon prepared from sugar beet bagasse. Bioresour Technol 101(6):1675-1680

Deng H, Yang L, Tao G, Dai J (2009) Preparation and characterization of activated carbon from cotton stalk by microwave assisted chemical activation-Application in methylene blue adsorption from aqueous solution. $\mathrm{J}$ Hazard Mater 166(2-3):1514-1521

Din ATM, Hameed BH, Ahmad AL (2009) Batch adsorption of phenol onto physiochemical-activated coconut shell. J Hazard Mater 161(2-3):1522-1529

Dursun AY, Tepe O, Uslu G, Dursun G, Saatci Y (2013) Kinetics of Remazol Black B adsorption onto carbon prepared from sugar beet pulp. Environ Sci Pollut Res 20(4):2472-2483

Hameed BH (2009) Evaluation of papaya seeds as a novel nonconventional low-cost adsorbent for removal of methylene blue. J Hazard Mater 162(2-3):939-944

Hameed B, El-Khaiary M (2008) Equilibrium, kinetics and mechanism of malachite green adsorption on activated carbon prepared from bamboo by $\mathrm{K}_{2} \mathrm{CO}_{3}$ activation and subsequent gasification with $\mathrm{CO}_{2}$. J Hazard Mater 157(2):344-351

Hameed B, Ahmad A, Aziz N (2009) Adsorption of reactive dye on palm-oil industry waste: equilibrium, kinetic and thermodynamic studies. Desalination 247(1):551-560

Ho Y, McKay G (1998) A comparison of chemisorption kinetic models applied to pollutant removal on various sorbents. Process Saf Environ Prot 76(4):332-340

Kaur P, Singh A, Prince A, Kushwaha J (2015) Optimization and evaluation of CBSOL LE red wool dye adsorption from aqueous solution onto commercial activated carbon. Int J Environ Sci Technol 12(12):3755-3766

Kennedy LJ, Vijaya JJ, Kayalvizhi K, Sekaran G (2007) Adsorption of phenol from aqueous solutions using mesoporous carbon prepared by two-stage process. Chem Eng J 132(1):279-287

Kılıç M, Apaydın-Varol E, Pütün AE (2012) Preparation and surface characterization of activated carbons from Euphorbia rigida by chemical activation with $\mathrm{ZnCl}_{2}, \mathrm{~K}_{2} \mathrm{CO}_{3}, \mathrm{NaOH}$ and $\mathrm{H}_{3} \mathrm{PO}_{4}$. Appl Surf Sci 261:247-254

Langergren S, Svenska BK (1898) Zur theorie der sogenannten adsorption geloester stoffe. Veternskapsakad. Handlingar 24:1-39

Li D-Q, Shang J-J, Ma X-F, Zhu X-Y, Liu Z-Y (2013) Combined influence of extraction parameters on degree of esterification of sugar beet pulp pectin: a preliminary study. J Chem Soc Pak 35(5):1256-1259

Liao Q, Liu Q, Meng M, Zhao Y, Ji X, Kang C, Huang S (2011) Study on preparation of rice husk-based activated carbon and its adsorption of methylene blue. Chin J Environ Eng 5(11):2447-2452

Liu Q-S, Zheng T, Wang P, Guo L (2010) Preparation and characterization of activated carbon from bamboo by microwave-induced phosphoric acid activation. Ind Crops Prod 31(2):233-238

Ma X, Li D, Wu Z, Meng G, Wu Y, Zhang H, Liu Z (2014) Preparation of activated carbon from sugar beet pulp via microwave-assisted method. J Shihezi Univ (Natural Science) 32(3):349-354

Malekbala MR, Hosseini S, Kazemi Yazdi S, Masoudi Soltani S, Malekbala MR (2012) The study of the potential capability of sugar beet pulp on the removal efficiency of two cationic dyes. Chem Eng Res Des 90(5):704-712

McKay G, Porter JF, Prasad GR (1999) the removal of dye colours from aqueous solutions by adsorption on low-cost materials. Water Air Soil Pollut 114(3-4):423-438

Ozer A, Tumen F (2003) Cd (II) adsorption from aqueous solution by activated carbon from sugar beet pulp impregnated with phosphoric acid. Fresenius Environ Bull 12(9):1050-1058

Ponnusami V, Madhuram R, Krithika V, Srivastava SN (2008) Effects of process variables on kinetics of methylene blue sorption onto untreated guava (Psidium guajava) leaf powder: statistical analysis. Chem Eng J 140(1-3):609-613

Puziy A, Poddubnaya O, Martınez-Alonso A, Suárez-García F, Tascon J (2002) Synthetic carbons activated with phosphoric acid: II. Porous structure. Carbon 40(9):1507-1519

Saka C (2012) BET, TG-DTG, FT-IR, SEM, iodine number analysis and preparation of activated carbon from acorn shell by chemical activation with $\mathrm{ZnCl}_{2}$. J Anal Appl Pyrol 95:21-24

Samadi M, Rahman A, Zarrabi M, Shahabi E, Sameei F (2009) Adsorption of chromium (VI) from aqueous solution by sugar beet bagasse-based activated charcoal. Environ Technol 30(10): 1023-1029

Thitame P, Shukla S (2016) Adsorptive removal of reactive dyes from aqueous solution using activated carbon synthesized from waste biomass materials. Int J Environ Sci Technol 13(2):561-570

Tongpoothorn W, Sriuttha M, Homchan P, Chanthai S, Ruangviriyachai C (2011) Preparation of activated carbon derived from Jatropha curcas fruit shell by simple thermo-chemical activation and characterization of their physico-chemical properties. Chem Eng Res Des 89(3):335-340

Vadivelan V, Kumar KV (2005) Equilibrium, kinetics, mechanism, and process design for the sorption of methylene blue onto rice husk. J Colloid Interface Sci 286(1):90-100

Vučurović VM, Razmovski RN, Tekić MN (2012) Methylene blue (cationic dye) adsorption onto sugar beet pulp: equilibrium isotherm and kinetic studies. J Taiwan Inst Chem Eng 43(1):108-111

Wang T, Tan S, Liang C (2009) Preparation and characterization of activated carbon from wood via microwave-induced $\mathrm{ZnCl}_{2}$ activation. Carbon 47(7):1880-1883

Wang L, Zhang J, Zhao R, Li C, Li Y, Zhang C (2010) Adsorption of basic dyes on activated carbon prepared from Polygonum orientale Linn: equilibrium, kinetic and thermodynamic studies. Desalination 254(1):68-74

Xiao H, Peng H, Deng S, Yang X, Zhang Y, Li Y (2012) Preparation of activated carbon from edible fungi residue by microwave assisted $\mathrm{K}_{2} \mathrm{CO}_{3}$ activation-Application in reactive black 5 adsorption from aqueous solution. Bioresour Technol 111:127-133

Yang K, Peng J, Srinivasakannan C, Zhang L, Xia H, Duan X (2010) Preparation of high surface area activated carbon from coconut shells using microwave heating. Bioresour Technol 101(15):6163-6169

Zhong Z-Y, Yang Q, Li X-M, Luo K, Liu Y, Zeng G-M (2012) Preparation of peanut hull-based activated carbon by microwaveinduced phosphoric acid activation and its application in Remazol Brilliant Blue $\mathrm{R}$ adsorption. Ind Crops Prod 37(1):178-185 